ISSN 1112-9867

Available online at

http://www.jfas.info

\title{
ANALYSIS OF METALLURGICAL ASPECTS AND THEIR ROLE IN PROCESSING AND PERFORMANCE OF SUPERALLOYS: A REVIEW
}

\author{
S. S. Raza*, T. Ahmad, M. U. Manzoor, M. Kamran, R. Ahmad
}
Department of Metallurgy and Materials Engineering, CEET, University of the Punjab, Lahore, Pakistan

Received: 10 September 2016 / Accepted: 27 December 2016 / Published online: 01 January 2017

\begin{abstract}
Metallurgical processing factors like kinetic and thermodynamic parameters which are essential for modeling of $\gamma^{\prime}$ phase precipitation have been studied. These parameters include $\gamma^{\prime}$ solvus temperature, Gibbs free energy of dissociation of the $\gamma$ matrix to form $\gamma^{\prime}$, nucleation rate, effective diffusivity and interfacial energy. Nucleation methods and effect of cooling rate on the final phase structure have been analyzed. Co based superalloys have been studied as a potential and promising material for aerospace applications. Effect of microporosity on the mechanical properties of Superalloys has also been analyzed.
\end{abstract}

Keywords: Superalloys, Precipitation, Solidification, Gamma prime, Microsegregation, Microporosity.

Author Correspondence, e-mail: hamdi.sahraoui @gmail.com

doi: http://dx.doi.org/10.4314/jfas.v9i1.27

\section{INTRODUCTION}

Nickel based superalloys are an important class of high temperature structural materials and find their applications in power generation systems and in jet engines. Superalloys are typically synthesized via ingot metallurgy (IM), powder metallurgy (PM) and investment casting (IC) methods $[1,2]$ depending on alloy content intended service. Alloys which are not susceptible to 
thermal cracking or macro segregation are usually processed via the ingot metallurgy. Processing temperatures for nickel based superalloys must be chosen above which all precipitates are dissolved. For instance, following powder synthesis and consolidation by blind-die compaction or hot isostatic pressing, $\gamma^{\prime}$-strengthened PM superalloys are usually extruded at a subsolvus temperature to develop a fine, recrystallized billet microstructure consist largely of $\gamma$ grains and primary $\gamma^{\prime}$ precipitates. The mean diameter of each phase is usually of the order of 1 to $5 \mu \mathrm{m}$. Alloys show a superplastic behavior with this microstructure under low strain rate processing conditions in the two phase field.

\section{First author corresponding e-mail address: sshahzadraza1472@gmail.com}

Subsequent heat -treatment techniques are chosen relative to the solvus temperature and depend on the service application. Heat treatment for $\gamma^{\prime}$ strengthened alloys consists of solution treatment below the $\gamma^{\prime}$ solvus temperature, forced or free air cooling to room temperature and final aging. The precipitates produced from such a heat treatment are denoted as primary, secondary and tertiary. The primary precipitates are obtained from prior subtransus processing during soaking at solution temperature, secondary form at higher temperatures during cooling followed by solution treatment while tertiary formed at lower temperatures during cool down and final aging. Excellent creep strength and crack growth resistance is achieved by a solution treatment consisting of supersolvus exposure to grow the $\gamma$ grain size. Secondary and tertiary precipitates are formed in this case on cooling [3].

Generally, the precipitation hardening is due to an ordered precipitates of $\gamma^{\prime}$ and $\gamma^{\prime \prime}$ L12 structure, and dispersed within the disorder $\gamma$ matrix in Fe- base superalloy. Precipitation hardening generates from an a/2 $\langle 110\rangle\{111\}$ dislocation travels in $\mathrm{g}$ matrix and form an anti-phase boundary (APB) in the $\gamma^{\prime}$ precipitates and therefore dislocation must move in pairs to remove the APB generated by the first dislocation. The anti-phase boundary energy is a $\gamma_{\mathrm{APB}}$ is a barrier which dislocations must overcome to cut the precipitates. Higher value of $\gamma_{\text {APB }}$ represents an order strengthening. This order strengthening shows a remarkable contribution due to stacking fault energy as compared to orwan strengtheing and creates a difference in modulus [4]. The microstructure of $\gamma$ and $\gamma^{\prime}$ phases is responsible for mechanical properties and mechanism of $\gamma^{\prime}$ precipitation is responsible for morphology, size, distribution and composition.

The dominant utilization of Ni-based superalloys generated a need to study binary and ternary $\gamma+$ $\gamma^{\prime}$ systems like Ni-Al, Ni-Al-Co, Ni-Al-Mo and Ni-Al-Cr alloys [5]. 
$\gamma^{\prime}$ is a primitive cubic, $\mathrm{L}_{2}$ crystal structure. $\mathrm{L}_{2}$ crystal structure has $\mathrm{Al}$ atoms at the cube corner and $\mathrm{Ni}$ atoms at the face centre in the binary $\mathrm{Ni}-\mathrm{Al}$ alloys as shown in Fig. 1. Each $\mathrm{Ni}$ atom has 8 $\mathrm{Ni}$ and $4 \mathrm{Al}$ atoms as nearest neighbor and each $\mathrm{Al}$ has $12 \mathrm{Ni}$ atoms surrounding it. The chemical composition of this system is $\mathrm{Ni}_{3} \mathrm{Al}$ and the lattice parameter a is $0.3570 \mathrm{~nm}$ at room temperature which is equal to an $\mathrm{Al}-\mathrm{Al}$ distance. Disorder $\gamma$ phase is $\sim 1.5 \%$ smaller than $\gamma^{\prime}$ lattice parameter. A change in lattice parameter occurs if the substitutions of other alloying elements occur and it depends on the size of the substitutes.

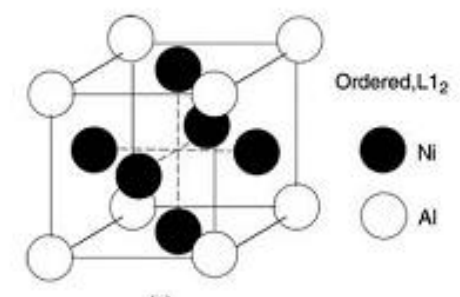

(a)

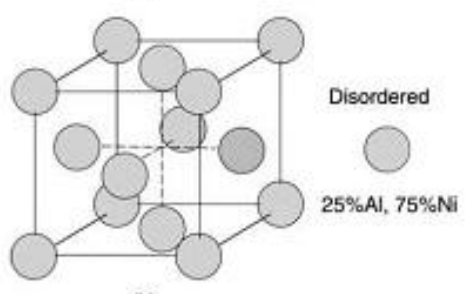

(b)

Fig.1. Arrangement of $\mathrm{Al}$ and $\mathrm{Ni}$ in a) ordered $\gamma^{\prime}$ phase with $\mathrm{L}_{2}$ structure and b) disorder $\gamma$ phase [6].

The $\gamma / \gamma^{\prime}$ interface remains coherent since the lattice parameter of the two phases is similar and the interfacial energy b/w the two is relatively low. Lattice misfit $\delta b / w$ the two phases is

$$
\delta=2\left(\alpha_{\gamma^{\prime}}-\alpha_{\gamma}\right)\left(\alpha_{\gamma^{\prime}}+\alpha_{\gamma}\right)
$$

where $\alpha_{\gamma^{\prime}}$ and $\alpha_{\gamma}$ are lattice parameters of $\gamma^{\prime}$ and $\gamma$ phases and it is common that the lattice misfit influences remarkably the properties of superalloys due to the coherency of the $\gamma / \gamma^{\prime}$ interface. In Ni-based alloys $\gamma^{\prime}$ precipitation has been generally categorized into homogeneous and heterogeneous nucleation. Homogeneous nucleation is spontaneous while heterogeneous nucleation occurs at preferential sites such as at grain boundaries. Abrupt or discontinuous change in composition and orientation $\mathrm{b} / \mathrm{w}$ the matrix and precipitates results in heterogeneous process. Decomposition temperature determines the type of nucleation. In a classical nucleation 
and growth process, homogeneous nucleation needs large driving force or undercooling to overcome a nucleation barrier or a critical nucleus size. There is a large compositional variation within a small region in classical nucleation process. This type of precipitation occurs within a near equilibrium composition as the critical nucleus forms. There is no hindrance in certain homogeneous solid-solid transformations for nucleation like phase separation via spinodal decomposition. If for instance quenching of $\gamma$ is done from a single $\gamma$ phase field undercooled and supersaturated $\gamma$ solid solution is unstable or metastable concerning ordering or phase separation. Solute rich and solute lean regions are produced from small composition fluctuations. It decreases the overall free energy of the system. It is obvious that the precipitation supported by spinodal decomposition takes place with non-equilibrium compositions of the matrix phases and precipitate in the early stages of the transformation. Both parent and precipitate phases existence support the Up-hill diffusion phenomenon. Following figure represents a general scheme of precipitation in Ni-based alloys.

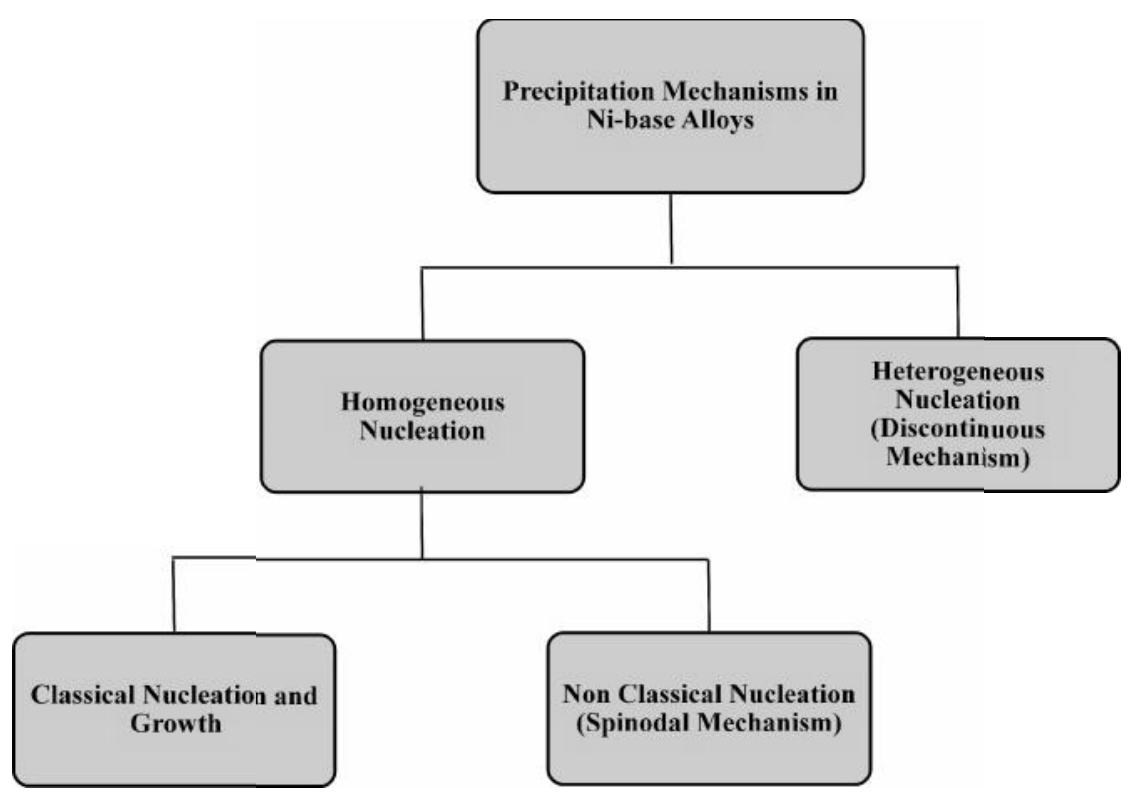

Fig.2. Schematic of precipitation mechanisms in Ni based alloys.

\section{Evolution of $\gamma^{\prime}$ Precipitates during Isothermal Annealing}

Ricks et al. [7] showed that with increasing annealing times the morphological evolution of $\gamma^{\prime}$ precipitates changes sequentially as spheres, cubes, arrays of cubes and finally dendrite and is 
found to be an effect of lattice misfit. $\gamma^{\prime}$ precipitates grow bigger before changing the morphology from spheres to cubes when the effect of misfit plays a vital role for alloys with low misfit. For instance in $\mathrm{Ni}-\mathrm{Al}-\mathrm{Cr}$ alloy substitution of $\mathrm{Cr}$ to $\mathrm{Ni}-\mathrm{Al}$ alloy retards the lattice misfit. In alloys like $\mathrm{Ni}-8 \mathrm{Al}-8 \mathrm{Cr}$ the misfit is nearly zero and thus $\gamma^{\prime}$ precipitates remain spherical to large spherical morphology after high temperature annealing [7].

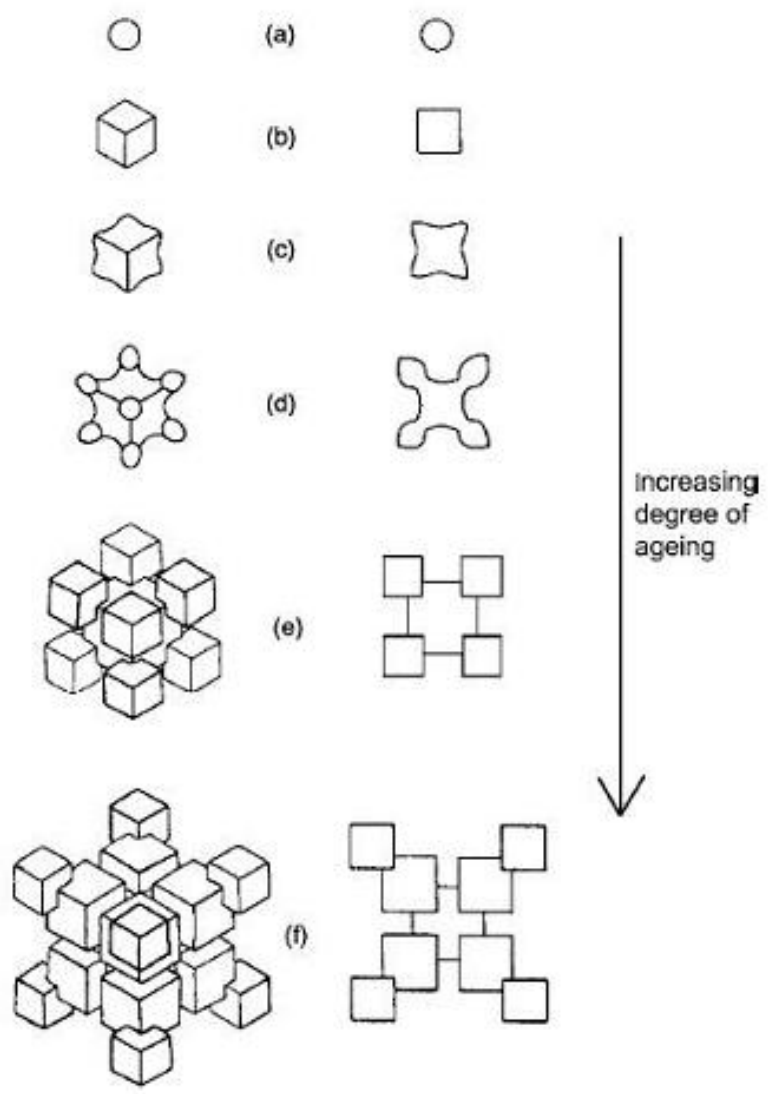

Fig.3. Illustration showing the evolution of $\gamma^{\prime}$ precipitates during isothermal annealing [7].

\section{Fundamentals of precipitation modeling}

Generally modeling procedures for precipitation rely on classical relations for the rate of homogeneous nucleation, static coarsening and diffusional growth.

\subsection{Nucleation Rate}


A general equation for the rate of nucleation of precipitates, $\mathrm{J}$, is given by the following equation $[8,9,10]$

$$
J=2 C D / a_{0} 4 \sqrt{\sigma} / K_{B} T \cdot \exp \left(-4 \pi \sigma r^{*} / 3 K_{B} T\right) \cdot \exp (-\tau / t)=J_{o} \exp (-\tau / t)
$$

in which $\mathrm{C}$ represents the solute content in the matrix as an atomic fraction, $\mathrm{a}_{\mathrm{o}}$ is the average lattice parameter of the matrix and precipitate phases (taken to be $\sim 0.356 \mathrm{~nm}$ for most $\gamma-\gamma^{\prime}$ superalloys), $\mathrm{D}$ is the solute diffusivity in the matrix phase, $\sigma$ is the matrix-precipitate surface energy $\mathrm{K}_{\mathrm{B}}$ is Boltzmann's constant $(1.3806 \mathrm{JK}-1)$, $\mathrm{T}$ is the temperature in Kelvin, and $\mathrm{t}$ is the time. The critical radius of the precipitate, $\mathrm{r}^{*}$, is a function of $\sigma$, the chemical free energy of transformation, $\mathrm{G}^{*}$ (taken to be a positive quantity for a decrease in energy), and the elastic strain energy, Gp, associated with the difference in lattice parameters of the matrix and precipitate phases, i.e.

$$
r^{*}=2 \sigma / \Delta G^{*}+\Delta G_{p}
$$

The nucleation rate $\mathrm{J}$ in the eq. 1 represents the steady state nucleation rate $\mathrm{J}_{\mathrm{o}}$ by the term $\exp$ $(-\tau / \mathrm{t})$ which states the primary nucleation transient during which a metastable distribution of embryos with a sub-critical radii are formed. Incubation time constant $\tau$ is given by the relationship below $[10,11]$ :

$$
\tau=\pi \mathrm{R} \mathrm{T} \mathrm{r}^{* 3} / 96 \mathrm{~V}_{\mathrm{M}} \mathrm{D} \sigma
$$

In which $\mathrm{V}_{\mathrm{M}}$ is the molar volume of the precipitate and $\mathrm{R}$ is the gas constant.

The above mentioned equations apply to nucleation in two component alloy system.

\subsection{Diffusional Growth}

The particles are assumed to be spherical having a radius $r$ with their growth controlled by diffusion in most theoretical treatments for $\gamma^{\prime}$ precipitates. The inter-diffusion is independent of composition and it is often assumed in fast acting simulations that the composition of the $\gamma^{\prime}$ precipitate is constant and equal to the average amount determined by the phase extraction.

The tendency for coarsening of larger secondary $\gamma^{\prime}$ precipitates is small due to retained supersaturation during continuous cooling at rates typical of production scale components. During aging, coarsening can be quite substantial. For multi-component alloys there is a general assumption that coarsening is controlled by the diffusion of a single rate limiting solute [12]. However, Voorhees and Kuehmann demonstrated that quickly diffusing solutes can also affect the coarsening rate and the associated diffusional processes for ternary alloys. Effective rate 
constant equal to the inverse of the sum of the inverse rate constants for the individual solutes as suggested by their work [13].

Essentially the important parameters for modeling of precipitation belong to one of the three parameters

1-Thermodynamic data

2- Driving/retarding forces for nucleation

\section{3-Kinetic factors/diffusivity}

The thermodynamic data comprises of solvus approach curve, the composition of $\gamma^{\prime}$ phase and the solute content in the matrix. The solute contents in the matrix depends largely on the volume fraction of composition and its precipitate [14]. In supersolvus solution treatments mainly secondary $\gamma^{\prime}$ nuclei form during a short time span during which the matrix composition undergoes a little change. Hence, $\mathrm{C}$ is usually constant and equal to 0.45-0.5.The largest values of the Gibbs free energy correspond to chromium among all of the alloys. The composition data suggests that this behavior may be ascribed to a very high level of solute partitioning $\mathrm{b} / \mathrm{w}$ the $\gamma$ and $\gamma^{\prime}$ phases for its element. The driving force for nucleation is the reduction in chemical free energy linked with the formation of $\gamma^{\prime}$ from a supersaturated $\gamma$ matrix. The important retarding force for nucleation consists of the creation of $\gamma-\gamma^{\prime}$ interfaces with their linked interfacial energy. The misfit energy may also act as a retarding force through its effect in enhancing the overall system energy in much the same way that the interface energy do as precipitates are formed. Usually its value is small relative to Gibbs free energy and can be neglected to a first order or implicitly added with energy values. The estimation of this energy is usually based on the temperature at which noticeable nucleation occurs [15].

In nickel based superalloys diffusivities of various solutes play a very vital role in the precipitation process by their effect on particle growth as well as their rate of depletion of matrix supersaturation controlling behavior. Since $\mathrm{Al}$ and Ti partition in a sense opposite to that of $\mathrm{Cr}$ in the $\gamma$ and $\gamma^{\prime}$ phases and the off-diagonal terms in the diffusivity matrix are non-zero, the produced concentration gradient for one alloying element can noticeably retard the overall diffusive flux of another. For instance, $\mathrm{Cr}$ and $\mathrm{Al}$ in a nickel solid solution have a positive interaction such that $\mathrm{Al}$ may diffuse down a chromium concentration gradient. The rate of diffusion of a given element to or away from the particle may be mitigated as a $\gamma^{\prime}$ precipitate grows, in a way by its ability to diffuse down the concentration gradient of a different alloying element. It is much more 
convenient to determine the effective diffusivity for the alloying elements whose behavior appears to be rate limiting and to which a simple diffusion analyses may be applied. Cr diffusion is rate limiting in $\gamma-\gamma^{\prime}$ superalloys for PM superalloys [16-18].

\section{Influence of cooling rate on the $\gamma^{\prime}$ Morphology and Size distribution}

Monomodal size distribution of refined $\gamma^{\prime}$ precipitates are formed as a result of faster cooling rates from $\gamma^{\prime}$ supersolvus temperatures. Otherway round slower cooling rates lead to the formation of $\gamma^{\prime}$ precipitates with a bimodal size distribution or in some cases even a multi modal size distribution. Bimodal distribution provides optimal mechanical properties for a turbine disk. Multiple distinct nucleation bursts at different undercooling below the $\gamma^{\prime}$ solvus are responsible for development of multiple size ranges of $\gamma^{\prime}$ precipitates during slow cooling or continuous cooling. These multiple nucleation bursts are a pure consequence of increasing thermodynamic force and chemical free energy difference which is due to reduction in the driving force due to previous nucleation events, increasing undercooling and the rapid declining diffusivity of alloying elements with decreasing temperature. Minimum driving force for nucleation together with elevated diffusivities lead to the initial burst of $\gamma^{\prime}$ nucleation at lower undercooling making the first generation of precipitates with minimum nucleation density and are designated as primary $\gamma^{\prime}$ precipitates. At low temperatures or higher undercooling minimum diffusivity of atoms lead to supersaturation of $\gamma^{\prime}$ and linked with a greater thermodynamic force generates more bursts of nucleation consequently forming secondary and in some cases tertiary precipitates with a very high nucleation density. Many authors are of a view that a trade off $b / w$ diffusion and undercooling rule the formation of the secondary precipitates and lower temperature leads to the formation of smaller particle size and higher number of particle density [19-22].

Single crystal Ni based superalloys has adroit mechanical stability at elevated temperatures due to their characteristic $\gamma / \gamma^{\prime}$ microstructure. The cuboidal crystal structure of $\gamma^{\prime}$-precipitates of $\mathrm{L}_{2} 2^{-}$ $\mathrm{Ni}_{3} \mathrm{Al}$ exists at the same time with a matrix of a disordered $\gamma$-phase on a coherent A1 crystal lattice. Sato et al. [23] noticed a common microstructure in the ternary Co-Al-W family with $\mathrm{L}_{2} 2^{-}$ $\mathrm{Co}_{3}(\mathrm{Al}, \mathrm{W}) \gamma^{\prime}$-precipitates in the $\gamma$ phase. After that Co-based single crystal superalloys are reviewed as a potential candidate for the next generation of elevated temperature superalloys. The flow behavior of these alloys is similar to Ni based superaloys. Parameters like $\gamma^{\prime}$ volume fraction, creep strength, characteristic phase transformation temperatures can be modified by alloying to reach the standards of Ni based superalloys. The formation of TCP phases reduce the 
$\gamma / \gamma^{\prime}$ strengthening effect and cause a rejection of strengtheners in the $\gamma$-matrix and this phenomenon is of great importance in alloy development.

$\mathrm{Ni}$ and Co based superalloys possesses as cast microstructures with a fourfold dendrite orientation perpendicular to the [001] growth direction. The as cast ERBOCo-0 sample structure of SEM sample normal to [001] axis is shown in the Fig.4.

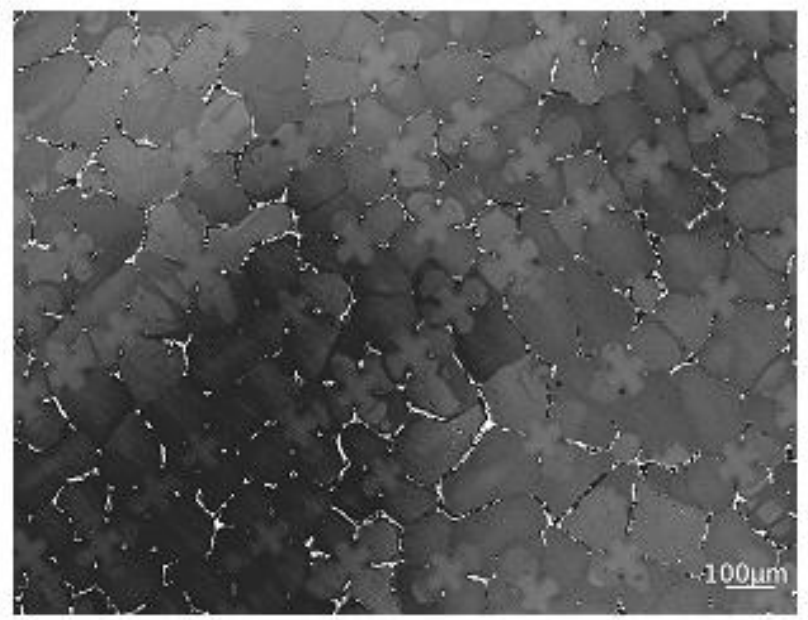

Fig.4. SEM image of cast microstructure of the Co based superalloy ERBOCo-0.

Intermetallic precipitates and microsegregation observed in the interdendritic regions are the main cause of difference in the as cast microstructure of alloys. Characterization by Electron Probe Microanalysis (EPMA) measurements quantify microsegregation during casting. The elemental distribution scheme of $\mathrm{Co}, \mathrm{Ti}, \mathrm{Ni}$ and $\mathrm{Al}$ of alloy ERBOCo-0 are shown in Fig 5. The results reveal that Co segregates into the dendritic core while $\mathrm{Ni}$, $\mathrm{Ti}$ and $\mathrm{Al}$ segregate into the interdendritic regions and this type of behavior is common in complicated Co based superalloys.

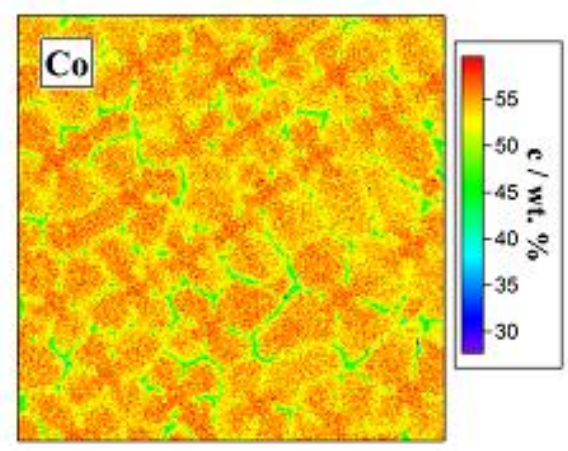

a)

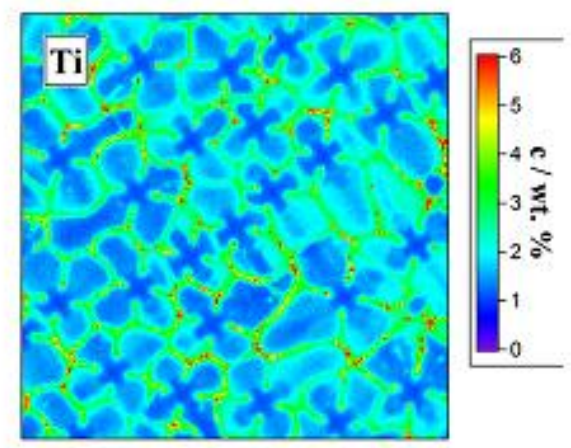

b) 


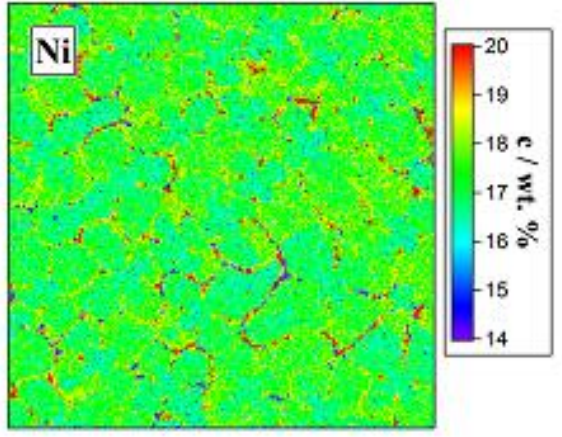

c)

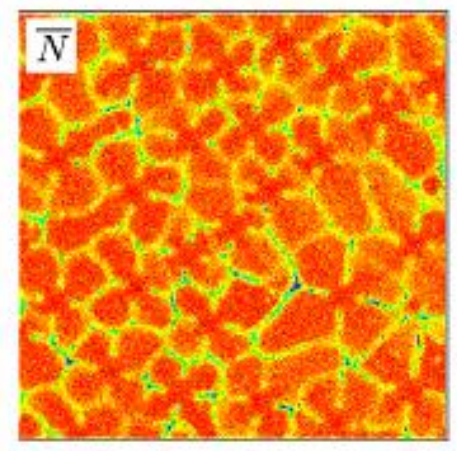

e)

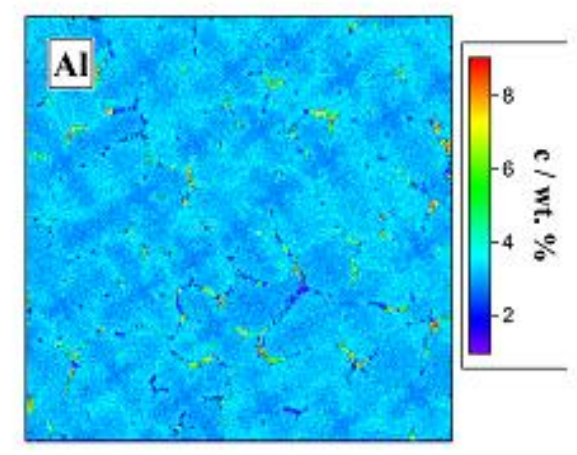

d)

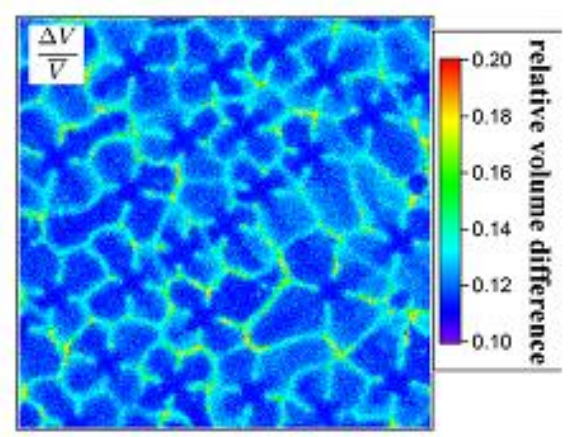

f)

Fig.5. EPMA scheme for the concentration of a) Co b) Ti c) Ni d) Al and their corresponding structure scheme co-ordinates e) $\mathrm{N}$ f) $\Delta \mathrm{V} / \mathrm{V}$.

The microsegregation of Ta into the interdendritic region is more common in Co based alloys as compared to the studied Ni based superalloys. This procedure may enhance the stability because it considers the convective instabilities during casting that are due to the density differences because of heavy elements segregating into the dendritic cores. Local enrichments in both the categories of superalloys can be similar. Secondary phase precipitation and heterogeneities are consequences of microsegregation during casting. These phases form in the interdendritic regions and this step occurs during the end of solidification. Fig.6 shows the formation of intermetallic phases in the interdendritic areas [23]. 


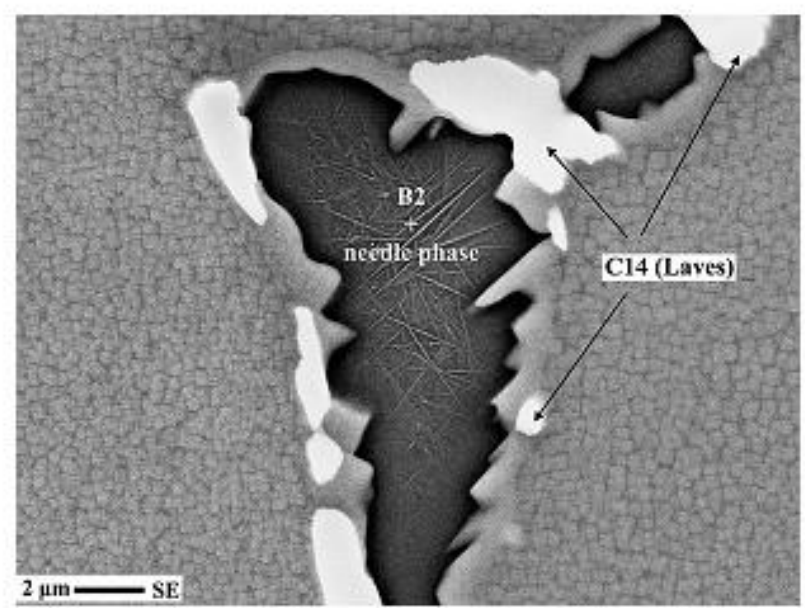

Fig.6. SEM image of an intermetallic precipitate in the $\gamma / \gamma^{\prime}$ microstructure of the interdendritic area [23]

Mechanical properties are greatly deteriorated by the porosity formation in castings. A good design of a feeding system may minimize the porosity defects. Redesigning of a feeding system is done according to the magnitude and location of porosity. A repetition may reduce porosity in the critical areas of castings. A shrinkage porosity which is due to the gas evolution and pressure drop during interdendritic fluid flow can be predicted by many models. Mushy zone region is a main area of study of microporosity formation. In liquid state pressure drop causes a shrinkage microporosity. Many alloys possess a higher density values in solid state as compared to liquid state. During a phase change from liquid to solid metal contraction takes place and solidification shrinkage occurs. Due to contraction pressure within the liquid drops and for a period cannot be compensated by a metallostatic pressure linked with the height of the liquid metal [24-25]. Simulation techniques, parametric or/and direct methods are usually apply to shape castings [2630].

\section{CONCLUSIONS}

The review studies focus on an insight of precipitation mechanisms of gamma prime phase and the factors which govern the phenomenon. Classical and non classical nucleation mechanisms 
and solid state transformations such as heterogeneous and homogeneous transformations have been studied. Scientific methods used to simulate nucleation, growth and coarsening of gamma prime have been formulated. Microsegregation for Co based and Ni based alloys have been discussed in the dendritic core and in interdendritic region. Shrinkage porosity has been discussed during solidification of superalloy castings.

\section{ACKNOWLEDGEMENTS}

The authors are thankful for the financial support of The University of the Punjab, Lahore, Pakistan.

\section{REFERENCES}

1. Donachie, M.J., Donachie,S.J.,2002. Superalloys: A Technical Guide. ASM International, Materials Park,USA.

2. Forbes Jones, R.M., Jackman, L.A., 1999. The structural evolution of superalloy ingots during hot working. JOM, 51(1), pp.27-31.

3. Semiatin, S, Zhang, F, Tiley, J, Furrer D, 2016. A comparison of the precipitation behavior in PM $\gamma-\gamma^{\prime}$ nickel-base superalloys. Materials at High Temperatures, pp.1-9.

4. Porter, D.A., Easterling, K.E., 1992. Phase transformations in metals and alloys. CRC Press.

5. Braszczyńska-Malik, K.N., May 2009. Discontinuous and Continuous Precipitation in Magnesium-Aluminium Type Alloys. Journal of Alloys and Compounds, 477(1), pp. 870-876 .

6. Reed, R. C., 2006. The Superalloys: Fundamentals and Applications. Cambridge University Press.

7. Rojhirunsakool, Tanaporn., 2014. Gamma prime precipitation mechanisms and solute partitioning in nickel base alloys. PhD Dissertation University of North Texas, USA.

8. Doherty, R.D., 1996. Diffusive phase transformations in the solid state. In: Cahn RW, Haasen P (eds) Physical Metallurgy, North-Holland Publishers, Amsterdam, ch. 15.

9. Aaronson, H.I., LeGoues, F.K., 1992. An assessment of studies on homogeneous diffusional nucleation kinetics in binary metallic alloys. Metall Trans A 23, pp.1915-1945.

10. Xiao, S.Q., Haasen, P., 1991. HREM investigation of homogeneous decomposition in a Ni-12 at.\% Al alloy. Acta MetallMater 39, pp.651 - 659 . 
11. Kampmann, L., Kahlweit, M., 1970. On the theory of precipitation II. Berichte der BunsenGesellschaft Physikalische Chemie 94, pp.456-462.

12. Grong, O., Shercliff, HR., 2002. Microstructural modelling in metals processing. Prog Mat Sci 47, pp.163-282.

13. Kuehmann, C.J., Voorhees, P.W., 1996. Ostwald ripening in ternary alloys. Metall Mater Trans A 27, pp.937-943.

14. Cao, W., Chen, S-L., Zhang, F., Wu, K., Yang, Y., Chang, Y.A., Schmid-Fetzer, R., Oates, W.A., 2009. PANDAT software with PanEngine, PanOptimizer and PanPrecipitation for multicomponent phase diagram calculation and materials property simulation. Calphad 33, pp.328342.

15. Semiatin, S.L., Kim, S-L., Zhang, F., Tiley, J.S., 2015. An investigation of high-temperature precipitation in powder-metallurgy, gamma/gamma prime nickel-base superalloys. Metall Mater Trans A 46, pp.1715-1730.

16. Dayananda, M.A., 1989. Multicomponent diffusion studies in selected high-temperature alloy systems. Mater Sci Eng A 121, pp.351 - 359.

17. Semiatin, S.L., Shank, J.M., Saurber, W.M., Pilchak, A.L., Ballard, D.L., Zhang. F., Gleeson, B., 2014. Alloying-element loss during high-temperature processing of a nickel-base superalloy. Metall Mater Trans A 45, pp.962- 979.

18. Campbell, C.E., Zhao, J.C., Henry, M.F., 2004. Comparison of experimental and simulated multicomponent Ni-Base superalloy diffusion couples. J Phase Equil Diff 25, pp.6- 15.

19. Tiley, J., Viswanathan, G.B., Srinivasan, R. et al., 2009. Coarsening Kinetics of $\gamma^{\prime}$ precipitates in the commercial nickel base Superalloy Rene 88 DT. Acta Materialia, 57(8), pp.2538-2549.

20. Caron, P., 2000. High $\gamma^{\prime}$ solvus new generation nickel based superalloys for single crystal turbine blade applications. Superalloys 2000, pp. 737-746.

21. Singh, A., Nag, S., Hwang, J. et al., 2011. Influence of cooling rate on the development of multiple generations of $\gamma^{\prime}$ precipitates in a commercial nickel base superalloy. Mater Character 62.

22. Booth -Morrison, C., Weninger, J., Sudbrack, C.K. et al., 2008. Effects of solute concentrations on kinetic pathways in Ni-Al-Cr alloys. Acta Materialia, 56(14), pp.3422-3438. 
23.Kobmann, J., Zenk, C. H., Kostka, A., et al., 2015. Microsegregation and precipitates of an as-cast Co-based superalloy- microstructural characterization and phase stability modeling, Journal of Materials Science 50, pp. 6329-6338.

24. Carlson, K. D., Beckermann, C., 2009. Metallurgical and Materials Transaction A 40 A, pp. 163-175.

25. Guo, J., Beckermann, C., Carlson, K., Hirvo, D., Bell, K., Moreland, T., Gu, J., Clews, J., Scott, S., Couturier, G. and Backman, D., 2015. Microporosity Prediction and Validation for Nibased Superalloy Castings. In IOP Conference Series: Materials Science and Engineering (Vol. 84, No. 1, p. 012003). IOP Publishing.

26. Zhang, H., Sun, L. and Zhan, D., 2015. Numerical Simulation of Solidification Structure Formation for a Large Flat Ingot during Water-cooled Mold Casting.

27. Sung, P.K., Poirier, D.R., Felicelli, S.D., Poirier, E.J. and Ahmed, A., 2001. Simulations of microporosity in IN718 equiaxed investment castings. Journal of crystal growth, 226(2), pp.363377.

28. Felicelli, S.D., Poirier, D.R. and Sung, P.K., 2000. A model for prediction of pressure and redistribution of gas-forming elements in multicomponent casting alloys. Metallurgical and Materials Transactions B, 31(6), pp.1283-1292.

29. Poirier, D.R., Yeum, K. and Maples, A.L., 1987. A thermodynamic prediction for microporosity formation in aluminum-rich $\mathrm{Al}-\mathrm{Cu}$ alloys. Metallurgical Transactions A, 18(11), pp.1979-1987.

30. Lee, P.D., Atwood, R.C., Dashwood, R.J. and Nagaumi, H., 2002. Modeling of porosity formation in direct chill cast aluminum-magnesium alloys. Materials Science and Engineering: A, 328(1), pp.213-222.

\section{How to cite this article:}

Raza S. S, Ahmad T, Manzoor M. U, Kamran M, Ahmad R. Analysis of metallurgical aspects and their role in processing and performance of superalloys: a review.J. Fundam. Appl. Sci., 2017, 9(1), 485-498. 